\title{
The Precursors and Products of Justice Climates: Group Leader Antecedents and Employee Attitudinal Consequences
}

David M. Mayer

Lisa H. Nishii

Benjamin Schneider

Harold Goldstein

Working Paper 07 - 09 


\title{
The Precursors and Products of Justice Climates: Group Leader Antecedents and Employee Attitudinal Consequences
}

\author{
David M. Mayer \\ University of Central Florida \\ Lisa H. Nishii \\ Cornell University \\ Benjamin Schneider \\ Valtera and University of Maryland \\ Harold Goldstein \\ Baruch College
}

March 2007

\section{http://www.ilr.cornell.edu/cahrs}

This paper has not undergone formal review or approval of the faculty of the ILR School. It is intended to make results of Center research available to others interested in preliminary form to encourage discussion and suggestions.

Most (if not all) of the CAHRS Working Papers are available for reading at the Catherwood Library. For information on what's available link to the Cornell Library Catalog: http://catalog.library.cornell.edu if you wish. 


\begin{abstract}
Drawing on the organizational justice, organizational climate, leadership and personality, and social comparison theory literatures, we develop hypotheses about the effects of leader personality on the development of three types of justice climates (e.g., procedural, interpersonal, and informational), and the moderating effects of these climates on individual level justice- attitude relationships. Largely consistent with the theoretically-derived hypotheses, the results showed that leader (a) agreeableness was positively related to procedural, interpersonal and informational justice climates, (b) conscientiousness was positively related to a procedural justice climate, and (c) neuroticism was negatively related to all three types of justice climates. Further, consistent with social comparison theory, multilevel data analyses revealed that the relationship between individual justice perceptions and job attitudes (e.g., job satisfaction, commitment) was moderated by justice climate such that the relationships were stronger when justice climate was high.
\end{abstract}

We would like to thank Mark Ehrhart, Quinetta Roberson, and Gary Shteynberg for their helpful comments on prior versions of this manuscript as well as Julie Lyon, Anuradha Ramesh and Amy Nicole Salvaggio for help in gathering the data. Direct correspondence to David M. Mayer, University of Central Florida, Department of Management, College of Business Administration, P. O. Box 161400, Orlando, FL 32803, Phone: 407-823-3209, Email: dmayer@bus.ucf.edu. 


\section{The Precursors and Products of Justice Climates: Group Leader Antecedents and Employee Attitudinal Consequences}

In recent years, research interest in organizational justice has grown, due to the recognition that justice perceptions have important attitudinal and behavioral outcomes such as organizational commitment, organizational citizenship behavior (OCB), evaluations of authority, job satisfaction, trust, and performance (Cohen-Charash \& Spector, 2001; Colquitt, Conlon, Wesson, Porter, \& Ng, 2001), and that, further, justice is a multidimensional and complex construct (Colquitt, 2001). One of the more recent and interesting areas of research related to organizational justice focuses on perceptions of climates for justice (Colquitt, 2004; Colquitt, Noe, \& Jackson, 2002; Colquitt, Zapata-Phelan, \& Roberson, 2005; Dietz, Robinson, Folger, Baron, \& Schulz, 2003; Ehrhart, 2004; Liao \& Rupp, 2005; Mossholder, Bennett, \& Martin, 1998; Naumann \& Bennett, 2000; Roberson \& Colquitt, 2005; Simons \& Roberson, 2003). Justice climate refers to a shared group-level cognition regarding the extent to which group members are treated fairly, and is typically operationalized as aggregate perceptions of justice across group members (Roberson \& Colquitt, 2005). This recent emphasis on justice climate is timely as it mirrors the growing trend of organizations to use more team-based structures (llgen, Hollenbeck, Johnson, \& Jundt, 2005; Kozlowski \& Bell, 2003).

To date, more research has been conducted on the consequences than antecedents of justice climates (see Colquitt et al., 2002 and Ehrhart, 2004 for exceptions)—and as such, a purpose of this study is to conceptualize and empirically explore precursors of justice climates. Expanding our knowledge of the antecedents of justice climates is critical, because only then can organizations purposefully facilitate the development of such climates and benefit from associated outcomes. We build on past research which has shown that unit leaders, as local implementers of organizational policies, influence followers' general climate perceptions (Lewin, Lippitt, \& White, 1939; Zohar, 2000; 2002; Zohar \& Luria, 2004), to argue that leaders also influence followers' justice perceptions. Surprisingly, little is currently known about the personal attributes of leaders that might be associated with the creation of justice climates, and to address this limitation, we draw on theory and research on organizational justice, leadership, 
and personality to develop several hypotheses about the relationship between leader personality and justice climates. Such research is important because by identifying leader personality characteristics that are related to justice climates, organizations can select fair managers in part based on their personality profiles.

In addition to exploring the influence of leader personality as an antecedent of justice climates, another goal of the current study is to examine justice climate as a boundary condition for individual-level justice effects. Past research has shown that after accounting for individual justice perceptions, justice climate is positively associated with unit members' job satisfaction, commitment, and OCB, suggesting that when a group's collective perceptions—or climate-are positive, positive individual-level outcomes will ensue (Liao \& Rupp, 2005; Mossholder et al., 1998; Naumann \& Bennett, 2000). This research preliminarily indicates that both individual justice perceptions and justice climate affect individual-level outcomes. Here, we draw on social comparison theory (Festinger, 1954) to examine the degree to which justice climate serves as a source of social comparison information and thus moderates the relationship between individual justice perceptions and individual job attitudes.

\section{Leadership and Subordinate Justice Climate Experiences}

One major goal of the present research is to examine leader personality as an antecedent of justice climates. Since the link between leadership and climate was first made by Lewin et al. (1939) and then McGregor (1960), research support for the role of leaders in the development of climate has mounted. For example, Schneider and Bowen (1985) found one of the first direct links between management practices and employee climate perceptions-in their case, involving service climate. Zohar's research (2000; 2002; Zohar \& Luria, 2004) suggests that managers impact subordinates' perceptions of climate vis-à-vis the way in which they implement organizational policies. Similarly, Offerman and Malamut (2002) posit that the way a leader implements organizational policies and models desired behavior influences subordinates' evaluations of organizational policies, and hence their climate perceptions. Together, these studies provide support for the notion that leaders play an important role in the development of 
climate, for they are the immediate source of the behavioral data on which employees base their views of organizational objectives and policies. Despite these theoretical and empirical advances, however, little research attention, with the exception of Ehrhart (2004) who found that servant leadership was positively related to a procedural justice climate, has been paid to leader characteristics as an antecedent of justice climates. This omission is curious given that nearly a half century ago McGregor (1960) devoted an entire chapter to what he called "managerial climate" and the essence of managerial climate for him was the issue of subordinates feeling fairly treated.

Organizational justice theory is largely premised on the idea that a set of justice rules is used by individuals to evaluate fair treatment, and the extent to which those rules are satisfied or violated determines perceptions of justice or injustice, respectively. The rules we speak of differ as a function of the dimension of justice under question, with a different set of rules being relevant for each dimension. In the present study we focus on three dimensions of justice (e.g., procedural, interpersonal, informational). Procedural justice, or the fairness of the procedures used to make decisions, is determined by the rules of voice (Thibaut \& Walker, 1975), as well as consistency, bias-suppression, accuracy, correctability, representativeness, and ethicality (Leventhal, 1980). Interpersonal justice, or the dignity and respect with which people feel they are treated, is assessed according to respect and propriety; while informational justice, which refers to the adequacy of explanations provided for decisions made, is determined by the provision of justifications and being truthful (Bies \& Moag, 1986; Greenberg, 1993). By understanding which types of leaders (i.e., leaders with certain personality traits) are likely to foster justice climates through their display of behaviors reflecting these rules, it may be possible to select leaders with these specific traits.

\section{Antecedents: Leader Personality and Justice Climates}

In this research we examine the effects of leader personality on justice climates via the Five Factor Model (FFM) of personality because of its acceptance in organizational research and because theoretically-driven hypotheses can be made linking some of the specific 
dimensions of the FFM-Agreeableness, Conscientiousness, Neuroticism, Extraversion, and Openness to Experience-with the emergence of procedural, interpersonal, and informational justice climates. Because no empirical research to date has been conducted on the relationship between leader personality and justice climates, we highlight conceptual links between the two and draw from indirect research support wherever possible. Rather than discuss all possible pairings between personality dimensions and justice climates, we focus only on those with strong underlying theoretical linkages.

Agreeableness. Agreeable individuals are described as sensitive, sympathetic, trustworthy, kind, gentle, and warm (Costa \& McCrae, 1992). Thus, a leader who is high on agreeableness is interpersonally oriented, easy to get along with, and sensitive to the needs of his or her subordinates, and, as a result, should be in a better position than leaders who are low on agreeableness to interact with subordinates in ways that engender perceptions of interpersonal and informational justice. With regard to interpersonal justice, it does not require much of an inferential leap to expect that the caring and sensitive disposition of agreeable leaders would make them likely to treat subordinates in a respectful manner, and to refrain from impropriety when interacting with them. In a feedback-giving situation, for example, the agreeable leader is likely to deliver feedback in ways that do not offend the subordinate, and to be sensitive about the concerns of the subordinate. In contrast, leaders who are low in agreeableness are known to be antagonistic, hostile, and argumentative (Costa, McCrae, \& Dembrowski, 1989); these traits parallel those that have been found to characterize abusive supervisors, who ridicule, blame, ignore, lie to, put down, and openly express anger towards, subordinates (Aquino \& Bradfield, 2000; Tepper, 2000; Tepper, Duffy, \& Shaw, 2000). Not surprisingly, then, we expect leaders who are low on agreeableness to treat their subordinates in ways that are less likely to engender perceptions of interpersonal justice.

Additional indirect support for the agreeableness-interpersonal justice relationship is evident in research on the FFM and transformational leadership. Research has shown that there is a significant positive relationship between agreeableness and the individual consideration 
component of transformational leadership (Judge \& Bono, 2000). This line of research is relevant because if agreeableness-in particular, its subfacets of trust, straightforwardness, altruism, and tender-mindedness - is associated with the tendency of leaders to support the individual needs of followers, and showing such concern and sensitivity to followers is associated with perceptions of interpersonal justice, then we can infer that agreeableness might be positively associated with interpersonal justice. In addition, Keller (1999) found that leaders who were high on agreeableness were rated by subordinates as having more sensitive qualities. These findings suggest that leaders high on agreeableness are likely to treat their subordinates with interpersonal sensitivity.

In addition to interpersonal justice, we think it is likely that agreeable leaders will be more apt to behave in ways that satisfy informational justice rules. In particular, because of their sympathetic and sensitive nature, we expect that out of concern for the needs of their subordinates, agreeable leaders will provide justifications to subordinates about their decisionmaking. In addition, given their trustworthiness and sensitivity, agreeable leaders are more likely to be truthful in communicating with subordinates and more likely to tailor such communications based on the specific needs of subordinates. Although empirical research has yet to examine the agreeableness-informational justice link, based on the theoretical links just described, we hypothesize:

Hypothesis 1: There will be a positive relationship between leader agreeableness and interpersonal and informational justice climates ${ }^{1}$.

Conscientiousness. Conscientious individuals are dependable, dutiful, prepared, detailoriented, and achievement-oriented (Costa \& McCrae, 1992). Thus, we expect that conscientious leaders will be more likely to satisfy many of the rules used to govern evaluations of procedural and informational justice. In terms of procedural justice, because conscientious leaders tend to be detail-oriented, it is likely that they will attend to the kind of detail required to implement procedures consistently across all of their subordinates. Any discrepancies in the 
implementation of decision-making procedures are likely to be "caught" by leaders who are prepared and prefer order and consistency in their lives. In support of this notion, Bass (1990) suggests that leaders who exhibit task competence-a reasonable assumption for highly conscientious leaders compared to less conscientious leaders-are more likely to act in ways that consistently facilitate success for the whole group. This is relevant for procedural justice given that consistency in treatment is one of the key standards for judging procedural justice.

The tendency of conscientious leaders to make lists, prioritize, and plan for the future will help them ensure that decisions are made based on accurate information. Indeed, Leventhal (1980, p. 42) states that "record keeping is an important method for accurate monitoring of behavior..." In addition, we expect that the principled and dutiful nature of conscientious leaders might make them more likely to keep abreast of policies and follow established protocol as part of their roles, and be more diligent about considering all relevant information when making decisions, thereby making decisions based on procedures likely to be perceived as more ethical by their followers.

In addition to being more likely to satisfy procedural justice rules than their lowconscientiousness counterparts, we expect conscientious leaders to satisfy rules used to govern informational justice. Because conscientious leaders are more organized, punctual, and exacting in their work, we expect them to provide timely, thorough justifications to their subordinates. This is because in an effort to stay organized and on top of things, conscientious leaders need to have access to complete information in a timely manner; we think it is likely that a leader with this inclination will also afford subordinates the same opportunity to have detailed, timely information regarding decisions that impact them. They may even see it as part of their duty to share important information with others. In addition, the dutiful nature of conscientious leaders should make it more likely that the information they provide to subordinates is truthful in nature. In support of the link between conscientiousness and informational justice, Sheppard and Lewicki (1987) found that conscientious leaders are more likely to communicate important news to their subordinates. In sum, we hypothesize: 
Hypothesis 2: There will be a positive relationship between leader conscientiousness and procedural and informational justice climates.

Neuroticism. Neurotic individuals are described as anxious, fearful, depressed, irritable, stressed, and moody (Costa \& McCrae, 1992). They tend to worry about unpleasant situations that may arise, react emotionally to unexpected or difficult situations, and take considerable time to return to an emotionally stable or normal state after becoming anxious (Spangler, House, \& Palrecha, 2004). In comparison, leaders who are low on neuroticism—or emotionally stableare less volatile and react less negatively to events in the workplace. Accordingly, because of the many detrimental behavioral consequences of a leader high on neuroticism, we expect neurotic leaders to be less likely to satisfy procedural, interpersonal, and informational justice rules.

In terms of procedural justice, due to their less stable demeanor, we expect that leaders high on neuroticism will be less likely to treat subordinates in a consistent manner because they will be more consumed with self-focused emotions (i.e., feeling anxious, depressed, stressed) and therefore less consistently available to focus on the needs of their subordinates. In other words, just as their moods are unstable, their ability to ensure consistent procedures will also likely be unstable. Indeed, because mood changes are common among neurotic individuals, it is likely that neurotic leaders will treat group members differently depending on their current mood state.

We also expect that leaders who are low on neuroticism will be more likely to provide their subordinates with opportunities to express their own concerns (i.e., have voice) because they will be less likely than their neurotic counterparts to be overwhelmed or made anxious by the concerns or demands of others. Given that the daily events in the life of a manager are often dynamic, rather than stable, the daily fluctuations to which managers are exposed are likely to be taxing for neurotic leaders who are predisposed to anxiety; subsequently they will be less likely to have the cognitive and emotional resources to consider their followers' needs. Finally, we also expect neurotic leaders to be less likely to satisfy the accuracy procedural justice rule. 
Since they are more likely to be preoccupied by feelings of sadness or anxiety, stress, and irritability, we reason that it will be more difficult for them to attend to all information necessary to make accurate decisions.

Empirical and theoretical support for the negative relationship between leader neuroticism and procedural justice comes from the literature on organizational trust. Research has shown that leader self-confidence is important for gaining the trust of followers (Kirkpatrick \& Locke, 1991), and that followers' trust in their leaders plays an important role in the formulation of procedural justice perceptions (Lind, 2001; Lind \& Tyler, 1988). Thus, if, as stated previously, neurotics tend to be less confident and more emotionally and behaviorally unstable, it follows that they may be less able to instill trust in their followers, and that consequently, followers' perceptions of procedural justice will suffer.

In addition, the tendency of neurotic individuals to react emotionally to unexpected or difficult situations may make them less able to be other-focused, a characteristic that is critical for treating others with respect. As a result, they may lack sensitivity in their interactions with their subordinates, at least in comparison with their emotionally stable counterparts, thereby making it less likely for their subordinates to experience interpersonal justice. Similarly, because neurotic individuals are easily disturbed, irritated, and made upset, they may be more likely to lash out and lack propriety when responding to subordinates' needs or request. As supported by the literature on abusive supervision, public criticism, rudeness, and inconsiderate actions that are likely to result from a leader that is stressed, irritable, and reactive, should have a detrimental effect on interpersonal justice (Bies 2001; Bies \& Tripp, 1998).

Finally, with regard to informational justice, neurotic leaders may be less likely to provide relevant information or justifications to subordinates about important decisions. To start, in situations when unfavorable news must be delivered to subordinates, neurotic leaders may be less likely to carry through, due to felt anxiety and discomfort on their part from anticipating the difficult situation and having to endure potentially negative reactions from their subordinates. Thus, they may select to share only information which is easy to share, or which does not have 
the potential to be emotionally charged. For similar reasons, the information that is shared with subordinates may be less truthful. Another possibility is that if and when they do venture to share difficult information, their tendency to be stressed, anxious, and irritable may inhibit the ability of neurotic leaders to share that information with subordinates in a way that is effective and understandable. Accordingly, we hypothesize that:

Hypothesis 3: There will be a negative relationship between leader neuroticism and procedural, interpersonal, and informational justice climates.

Extraversion. Extraverted individuals are described as sociable, talkative, positive, warm, active, assertive, and ambitious (Costa \& McCrae, 1992; Goodstein \& Lanyon, 1999); in other words, they are socially-oriented. Because of this emphasis on social interaction, we expect that extraverted leaders will communicate more with their subordinates than will introverted leaders. Because a key medium for employees to voice their opinions is through discussions with their leaders, we expect that leader extraversion may be associated with procedural justice by making it more likely for followers to have voice. This assertion is supported by research which has shown a positive relationship between extraversion and a "value for voice" (Avery, 2003). Thus, given extraverted leaders' inclination for self expression, it is likely that such leaders would afford their followers the opportunity to express their concerns.

Hypothesis 4: There will be a positive relationship between leader extraversion and procedural justice climate.

The fifth factor of personality within the FFM is openness to experience, which involves being imaginative, creative, and intellectual (Costa \& McCrae, 1992). We have little theoretical reason to expect a significant relationship between this dimension and justice, and thus we do not present any hypotheses. 


\section{Consequences: The Interactive Effect of Justice Climates and Individual Justice Perceptions}

In addition to examining the leader attributes that are antecedent to the development of justice climates, another aim of our study was to build upon existing research on the outcomes of justice climates by exploring the moderating role of justice climates on the relationship between individual justice perceptions and individual outcomes (e.g., job satisfaction, commitment). Research on justice climate has shown that shared perceptions of justice at the group level are also positively related to individual outcomes such as job satisfaction, commitment, and OCB, over and above the effects of individual justice perceptions (Liao \& Rupp, 2005; Mossholder et al., 1998; Naumann \& Bennett, 2000). These findings are important because they highlight the fact that valued outcomes, like feeling justly treated, are influenced not only by individuals' own perceptions but also by collective perceptions of justice. However, this research has implicitly assumed that regardless of how an individual feels s/he is treated, if the groups' collective justice perceptions are favorable, then an individual's attitudinal and behavioral outcomes will also be favorable (see Colquitt, 2004 for an exception).

Social comparison theory (i.e., Festinger, 1954) provides an alternative lens through which to view the relationship between individual justice perceptions, justice climate, and individual outcomes. The link between justice and social comparison processes is not new, as social comparison processes are a recognized component of equity theory (Adams, 1965), relative deprivation theory (Crosby, 1976), referent cognitions theory (Folger, 1986), and its successor, fairness theory (Folger \& Cropanzano, 1998; 2001). A common thread through this work is the idea that when individuals look to others for social comparison information, they tend to choose referents in their immediate social world (Shah, 1998). This reasoning suggests that employees will look to others in their work group for social comparison information. Indeed, (Shah, 1998, p. 252) states that, “... social information enables individuals to assess their acceptance in work groups." Individuals may not however always limit their search to the experiences of specific others in their work groups and research supports the notion that 
individuals are also impacted by aggregate sources of social comparison, such as the climate that pervades one's work group (Buckingham \& Alicke, 2002).

Drawing on this work on social comparison theory, our premise in the present effort is that group members are influenced not only by their own justice perceptions, but also by how fairly the group as a whole is treated. We propose that the relationship between justice perceptions and individual outcomes is stronger when justice climates are high. The groupvalue model of justice (Lind \& Tyler, 1988; Tyler \& Lind, 1992), and fairness theory (Folger \& Cropanzano, 1998; 2001) help to explain why this would be the case. The group-value model of justice posits that one reason people are concerned with being treated in a just manner is because it signals to them how much they are valued by their leader and the group. By using justice climates as social comparison information, individuals can compare their treatment to the treatment of others to determine their perceived worth in the eyes of their leader, or by management more generally. Fairness theory further posits that individuals ask themselves three questions (or "counterfactuals") when deciding whether an event is fair: Would another situation have felt better?; Could anything have been done about it?; and Should anything have been done about it?. This issue of counterfactuals is relevant because individuals pay attention to whether there is a discrepancy between their treatment and the treatment of the rest of the group. If an individual's treatment is less favorable, one is likely to feel that being similarly treated would have felt better, and that perhaps something could and should have been done to prevent that discrepancy from occurring. Such relative judgments likely lower perceptions of justice.

These two theories suggest that when justice climates are high (or positive), individual justice perceptions should be more strongly associated with individual outcomes. When an individual has high justice perceptions, and the group as a whole is treated fairly (i.e., justice climate is high), this should increase the individual's satisfaction and commitment to the organization, since the fact that both the individual and the group are treated well signals that employees are highly valued by the organization (Lind \& Tyler, 1988; Tyler \& Lind, 1992). 
However, when the group as a whole experiences a positive justice climate but an individual perceives that $\mathrm{s} / \mathrm{he}$ is treated unfairly, it suggests to the employee that $\mathrm{s} / \mathrm{he}$ may not be a valued member of the group relative to the others (Lind \& Tyler, 1988; Tyler \& Lind, 1992). In addition, consistent with fairness theory (Folger \& Cropanzano, 1998; 2001), when an individual who is treated unfairly asks the "could" counterfactual (i.e., Could anything have been done about my treatment?), s/he must answer in the affirmative because others have received more favorable treatment, and thus satisfaction and commitment will be less favorable.

In contrast, when the justice climate is low, we expect the relationship between individual justice perceptions and individual outcomes to be attenuated. When an individual perceives fair treatment but the group as a whole is treated unfairly, it suggests that all employees may not be equally valued. Taking it a step further, the potential for the individual to not be treated fairly in the future seems like a more realistic possibility, and thus the positive relationship between his/her justice perceptions and attitudinal outcomes may be attenuated. Indeed, if there is disparity in how group members are treated, even for individuals who are treated fairly, internal conflict within the group about such differentiation could hurt individual attitudes (Scandura, 1999). However, when an individual has low justice perceptions and the group is also low on justice, that individual can externalize the reason why his or her treatment is low. For example, that individual can attribute the unfair treatment to "that's just how they treat people around here" as opposed to "others are treated well but I'm treated unfairly so they must not value me." In line with fairness theory, given that everyone is treated unfairly, it is less clear whether anything "could" have been done, and consequently individual attitudes are not as unfavorable.

There is some empirical support for the notion that one's own justice perceptions and others' justice perceptions interact to impact individual-level outcomes. Research has demonstrated that when other people's justice perceptions are high, the relationship between one's own justice and individual outcomes is stronger (Colquitt, 2004; Grienberger, Rutte, \& van Knippenberg, 1997; van den Bos \& Lind, 2001). Although this research did not examine justice climates per se, but rather others' individual-level perceptions of a referent other or one's team, 
the nature of the interactions found provides justification for our hypothesis. In sum, we hypothesize:

Hypothesis 5: The positive relationship between individual procedural, interpersonal, and informational justice perceptions on (a) job satisfaction and (b) commitment will be moderated by justice climates, such that the relationship between individual justice perceptions and individual job attitudes will be stronger when justice climates are high. ${ }^{2}$

\section{Method}

\section{Participants}

Participants in this study were 3445 employees (40\% response rate) in 383 departments (e.g., meat, deli, bakery) from stores in a grocery store chain on the East coast. In addition to these employees, 194 department managers from the departments of which the employees were members participated in the study. In terms of the racial demography of the employees, $81 \%$ were White, $5 \%$ African American, $1 \%$ Hispanic, 1\% Asian, and 2\% "other," while 9\% did not provide demographic data. In terms of gender, $35 \%$ were male, $56 \%$ indicated female, and $9 \%$ had missing data. In terms of age, $10 \%$ were under $18,18 \%$ were between $18-22,10 \%$ were $23-29,16 \%$ were $30-39,38 \%$ were above 40 , and $9 \%$ did not provide data. Over half $(58 \%)$ of the employees had been employed at the company for more than three years. Of the department managers, $95 \%$ were Caucasian, $45 \%$ were male and approximately $60 \%$ had been with the company for over three years.

\section{Procedure}

Employees responded to survey items regarding their perceptions of the three types of justice (e.g., procedural, interpersonal, informational), job satisfaction, and commitment. The department managers filled out a separate self-report measure of personality. The surveys were distributed by the organization to employees and department managers while they were at work, and all participants were given the opportunity to fill out the survey during working hours. Completed surveys were then mailed back to the primary investigator of the project in order to ensure confidentiality. 
Through our prior work with the organization and focus groups we conducted related to the current study, we were aware that the corporate focus of the participating organization is on departments rather than stores. To corroborate this notion, the organization collects all performance indices at the department level of analysis. Because the focal unit of analysis was departments within stores, we aggregated the justice data from individual employees to the department level of analysis. In an effort to have reliable justice climate measures, we only used departments that had four or more employees (Bliese, 2000). We then matched the department manager personality data with the aggregated justice data so that we had a group-level database to examine hypotheses 1-4 with a total of 194 departments for which we had matched data. Finally, we created an individual level database that included individual justice perceptions, job satisfaction, and commitment as well as measures of department justice climates matched back to each individual, providing a final sample of 3,432 individuals in 383 departments. In sum, 194 departments were used for the first set of hypotheses involving leader personality, and 383 departments were used for the final hypothesis that examined the interaction between individual justice perceptions and justice climates.

\section{Measures}

Leader personality. Dimensions of the FFM were examined in this study using the Goldberg measure of personality (Goldberg, 1999). In this publicly available measure each dimension is assessed by calculating a mean score on ten items. Responses for all items were made on a five-point scale, ranging from " $1=$ to no extent to $5=$ to a great extent." A sample item for agreeableness is, "I sympathize with others' feelings," and the alpha for the scale was .79. A sample item for conscientiousness is, "I am always prepared," and the alpha for the scale was .78. A sample item for neuroticism is, "I worry about things a lot," and the alpha for the scale was .84. A sample item for extraversion is, "I feel comfortable around people," and the alpha for the scale was .82.

Justice climate. Procedural, interpersonal, and informational justice were assessed with Colquitt's (2001) measure of organizational justice. Procedural justice items were changed from 
the individual to group level of analysis by asking employees to report on what goes on in their department, which is the norm for research on procedural justice climate (Colquitt et al., 2002; Ehrhart 2004; Naumann \& Bennett, 2000). Interpersonal and informational justice items were kept intact except that employees were explicitly asked about their department manager in line with recent published research on interpersonal and informational justice climates (Liao \& Rupp, 2005; Simons \& Roberson, 2003). Because of space limitations on the survey, most but not all of the scale items were used. Responses for all items were made on a five-point scale, ranging from " $1=$ to no extent to $5=$ to a great extent." After asking respondents to consider the procedures that are used to make daily decisions in their departments, four items were used to assess procedural justice, including, "Have those procedures been applied consistently?" The alpha for procedural justice was .88. Three items were used to assess interpersonal justice in one's department, including, "Has your manager treated you with respect?" The alpha for interpersonal justice was .95. Three items were used to assess informational justice in one's department, including, "Has your manager explained the procedures thoroughly?" The alpha for informational justice was .86. Justice climate was operationalized as the mean of departmental employee perceptions regarding procedural, interpersonal, and informational justice.

A confirmatory factor analysis (CFA) was run to see if a three-factor solution fit the data better than a one-factor (all items in one factor) and a two-factor (procedural justice items in one factor and interpersonal and informational justice items in the other factor) solution. Results revealed that the three-factor solution had significantly better fit than the one-factor $\left(\Delta x^{2}=\right.$ 6302.87, $\mathrm{df}=3, p<.001)$ and two-factor solution $\left(\Delta x^{2}=4326.44, \mathrm{df}=1, p<.001\right)$. The CFA revealed that a three-factor solution with procedural, interpersonal, and informational justice as distinct but correlated factors revealed good fit $\left(X^{2}(32)=698.745, p<.001 ; \mathrm{CFI}=.976\right.$; SRMR $=$ .037 ; RMSEA $=.078$ ) so they were kept as three dimensions of justice in testing the hypotheses.

Job satisfaction. Overall employee satisfaction was the satisfaction construct of interest in this study, meant to capture employees' satisfaction with their overall position as an employee 
of a company. Specifically, we chose to measure global satisfaction using an adapted version of the gender-neutral single-item Faces Scale (Kunin, 1955). Respondents picked one out of five faces that best reflected their level of satisfaction with the job. The extremely happy face was given a score of 5 , the moderately happy face a score of 4 , the non-descript face a score of 3 , the moderately sad face a score of 2 , and the extremely sad face a score of 1 . Contrary to popular thought in our field that single-item measures are undesirable due to poor reliability, Wanous, Reichers, and Hudy (1997) concluded, based on a meta-analysis in which they utilized the correction for attenuation that, at a minimum, the estimated reliability for single-item measures of satisfaction is close to .70 , and that single-item measures are highly correlated with scale measures.

Organizational commitment. We assessed affective commitment with a four-item measure from Meyer and Allen (1991). Responses for all items were made on a five-point scale, ranging from " $1=$ to no extent to $5=$ to a great extent." A sample item includes, "I feel a strong sense of "belonging" to (Company name)." The alpha for the measure was .88.

\section{Data Analyses}

As hypotheses 1-4 all examined group-level relationships, they were tested with hierarchical regression. Because the hypotheses are directional, the relationship between each of the hypothesized personality dimensions and the justice climates were tested one at a time using one-tailed tests of significance. In contrast, hypothesis 5 examined the interactive effects of individual justice perceptions and justice climate on individual outcomes. Because individuals are nested within groups, it was important to use random coefficient modeling (RCM, commonly referred to as hierarchical linear modeling or HLM) to test hypothesis 5. This analytical approach is important because it allows for the partitioning of the within-group and between-group variance in the dependent variable. Consistent with recent multilevel theory (Klein, Dansereau, \& Hall, 1994; Klein \& Kozlowski, 2000), it is necessary to control for the nested nature of such data to provide a more powerful and accurate test of within-group relationships. The PROC MIXED function in SAS was used to conduct all of the RCM analyses (Singer, 1998). We also 
controlled for leader demographics (e.g., gender, race, tenure), group diversity (e.g., group gender diversity, group racial diversity, group tenure diversity), and group size in the hypotheses tests.

\section{Results}

\section{Descriptive Statistics}

The means, standard deviations, and intercorrelations among the key variables are presented in Table 1.

\section{Aggregation Statistics}

The median $r_{w g}$ value for procedural $\left(r_{w g}=.68\right)$, interpersonal $\left(r_{w g}=.61\right)$, and informational $\left(r_{w g}=.63\right)$ justice were all slightly below the .70 recommendation (George, 1990). The ICC values for procedural (ICC1=.15, ICC2=.62), interpersonal $(\mathrm{ICC} 1=.14, \mathrm{ICC} 2=.60)$, and informational (ICC1=.15, ICC2=.61) justice, were all statistically significant and the ICC1 values were generally above recommended levels—but the ICC2 values were slightly below the suggested cutoff (Bliese, 2000). Despite the fact that the $r_{w g}$ and ICC2 values were slightly below recommended levels, it is important to note that these "cutoffs" were determined somewhat arbitrarily and the climate literature has argued that climate should be considered on a continuum - as opposed to either existing or not existing (Lindell \& Brandt, 2000; Schneider, Salvaggio, \& Subirats, 2002).

\section{Tests of Hypotheses}

Results of hypotheses 1-4 regarding the relationship between leader personality and justice climates are reported in Table 2. Hypothesis 1 posited that leader agreeableness would be positively related to interpersonal and informational justice climates. One-tailed tests of significance revealed that the relationships between agreeableness and interpersonal justice climate $(\beta=.16, p<.05)$ and informational justice climate $(\beta=.17, p<.05)$ were significant. Although not predicted, agreeableness was also significantly related to procedural justice climate ( $\beta=.17$, $p<.05)$. When leaders were more agreeable they tended to lead groups that experienced more 
Table 1

Means, Standard Deviations, and Intercorrelations Among Key Variables

\begin{tabular}{|c|c|c|c|c|c|c|c|c|c|c|c|c|c|c|c|c|}
\hline & $M$ & $S D$ & 1 & 2 & 3 & 4 & 5 & 6 & 7 & 8 & 9 & 10 & 11 & 12 & 13 & 14 \\
\hline \multicolumn{17}{|l|}{ Individual-Level Measures } \\
\hline 1. Procedural Justice & 3.31 & .95 & - & & & & & & & & & & & & & \\
\hline 2. Interpersonal Justice & 4.10 & 1.04 & .53 & - & & & & & & & & & & & & \\
\hline 3. Informational Justice & 3.77 & 1.01 & .60 & .76 & - & & & & & & & & & & & \\
\hline 4. Job Satisfaction & 2.46 & 1.03 & .35 & .27 & .29 & - & & & & & & & & & & \\
\hline 5. Commitment & 2.80 & 1.14 & .44 & .28 & .34 & .50 & & & & & & & & & & \\
\hline \multicolumn{17}{|l|}{ Group-Level Measures } \\
\hline 1. Agreeableness & 4.17 & .58 & - & & & & & & & & & & & & & \\
\hline 2. Conscientiousness & 4.18 & .53 & .51 & - & & & & & & & & & & & & \\
\hline 3. Neuroticism & 3.61 & 67 & -38 & -31 & - & & & & & & & & & & & \\
\hline 4. Extraversion & 3.38 & .65 & .34 & .21 & -27 & - & & & & & & & & & & \\
\hline 5. Procedural Justice Climate & 3.35 & .55 & .11 & .15 & -15 & -01 & - & & & & & & & & & \\
\hline 6. Interpersonal Justice Climate & 4.11 & .58 & .12 & .10 & -19 & -04 & 69 & - & & & & & & & & \\
\hline 7. Informational Justice Climate & 3.78 & .57 & .14 & .08 & -14 & -11 & .78 & .84 & - & & & & & & & \\
\hline 8. Group Size & 9.00 & 7.71 & .06 & .00 & .03 & .01 & -10 & -01 & -04 & - & & & & & & \\
\hline 9. Group Gender Diversity & .31 & .20 & .03 & -.02 & .05 & .07 & -14 & -08 & -.07 & .26 & - & & & & & \\
\hline 10. Group Racial Diversity & .14 & .18 & .03 & .00 & -00 & -06 & -12 & -07 & .08 & .11 & .09 & - & & & & \\
\hline 11. Group Tenure Diversity & 1.25 & .43 & .00 & .15 & -07 & .04 & .01 & .05 & .06 & .12 & .03 & .07 & - & & & \\
\hline 12. Manager Gender & .46 & .50 & -24 & -10 & -00 & -14 & .02 & .06 & .06 & -14 & .09 & .08 & .24 & - & & \\
\hline 13. Manager Race & .99 & .22 & -06 & -10 & .05 & -06 & -03 & -03 & -09 & -04 & .03 & -11 & -18 & -06 & - & \\
\hline $\begin{array}{l}\text { 14. Manager Tenure } \\
\text { Note. } \\
\begin{array}{l}n=3,432 \text { individuals for all individual-- } \\
n=383 \text { groups for correlations betwee } \\
n=194 \text { groups for all correlations invo } \\
\text { Gender was coded } 1 \text { for male and } 0 \text { fo }\end{array}\end{array}$ & $\begin{array}{l}3.52 \\
\text { I correl } \\
\text { g leade }\end{array}$ & 1.38 & .00 & .09 & .07 & -10 & .08 & .04 & .13 & -06 & -09 & -08 & .06 & .21 & .04 & - \\
\hline
\end{tabular}


Table 2

Regressions with Leader Personality to Justice Climates

(Hypotheses 1-4)

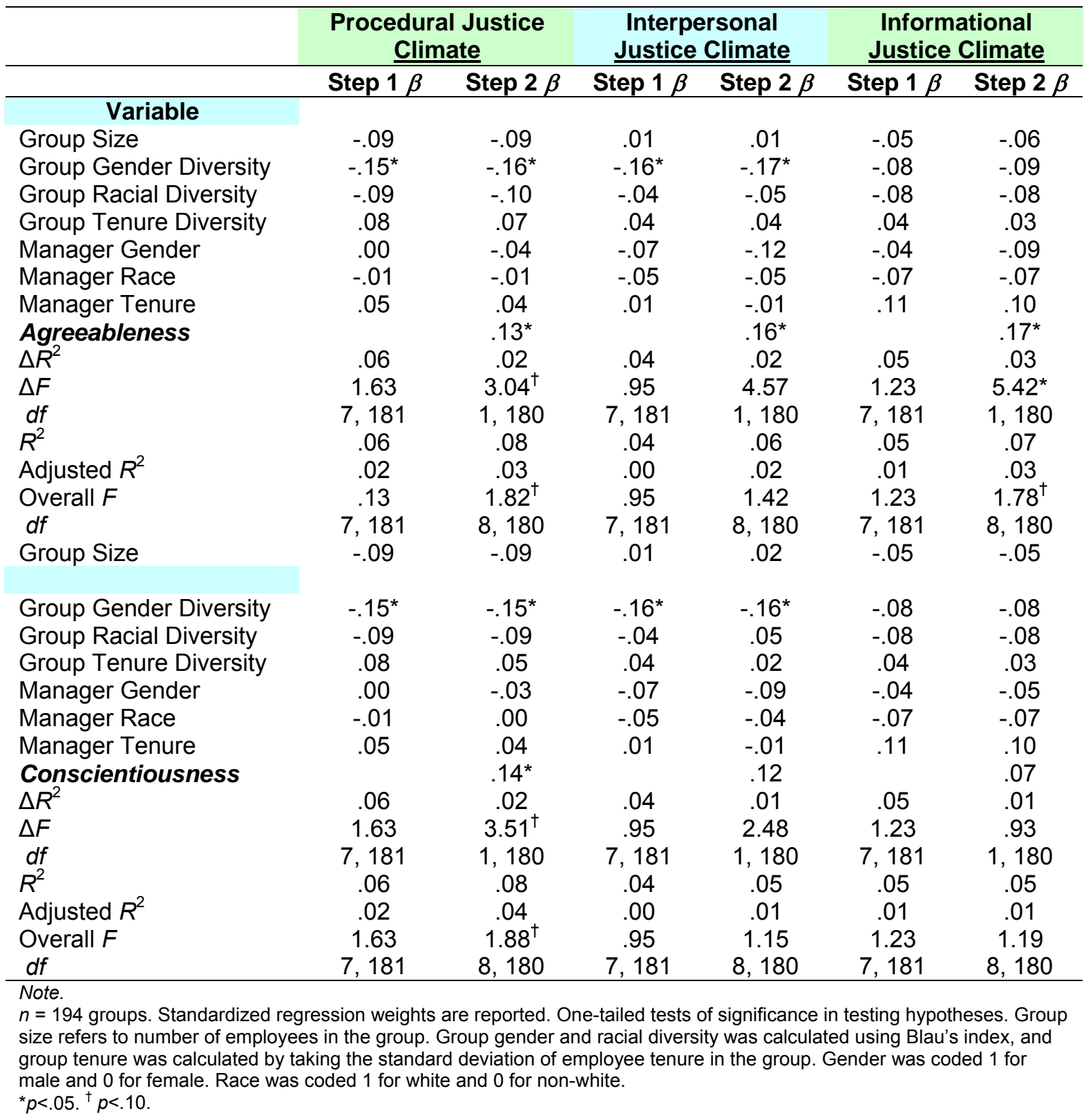


Table 2 (Ctd.)

Regressions with Leader Personality to Justice Climates

(Hypotheses 1-4)

\begin{tabular}{|c|c|c|c|c|c|c|}
\hline & \multicolumn{2}{|c|}{$\begin{array}{l}\text { Procedural Justice } \\
\text { Climate }\end{array}$} & \multicolumn{2}{|c|}{$\begin{array}{c}\text { Interpersonal } \\
\text { Justice Climate } \\
\end{array}$} & \multicolumn{2}{|c|}{$\begin{array}{c}\text { Informational } \\
\text { Justice Climate } \\
\end{array}$} \\
\hline & Step $1 \beta$ & Step $2 \beta$ & Step $1 \beta$ & Step $2 \beta$ & Step $1 \beta$ & Step $2 \beta$ \\
\hline \multicolumn{7}{|l|}{ Variable } \\
\hline Group Size & -.09 & -.09 & .01 & .02 & -.05 & -.05 \\
\hline Group Gender Diversity & $-.15^{\star}$ & -.14 & $-.16^{*}$ & $-.15^{\star}$ & -.08 & -.08 \\
\hline Group Racial Diversity & -.09 & -.09 & -.04 & -.05 & -.08 & -.08 \\
\hline Group Tenure Diversity & .08 & .07 & .04 & .03 & .04 & .04 \\
\hline Manager Gender & .00 & .00 & -.07 & -.07 & -.04 & -.04 \\
\hline Manager Race & -.01 & .00 & -.05 & -.04 & -.07 & -.07 \\
\hline Manager Tenure & .05 & .06 & .01 & .02 & .11 & 12 \\
\hline Neuroticism & & $-.15^{\star}$ & & $-.20^{\star *}$ & & $-.13^{*}$ \\
\hline$\Delta R^{2}$ & .06 & .02 & .04 & .04 & .05 & .02 \\
\hline$\Delta F$ & 1.63 & $4.10^{*}$ & .95 & $7.39^{* *}$ & 1.23 & $3.31^{\dagger}$ \\
\hline$d f$ & 7,181 & 1,180 & 7,181 & 1,180 & 7,181 & 1,180 \\
\hline$R^{2}$ & .06 & .08 & .04 & .07 & .05 & .06 \\
\hline Adjusted $R^{2}$ & .02 & .04 & .00 & .03 & .01 & .02 \\
\hline Overall $F$ & 1.63 & $1.96^{*}$ & .95 & $1.79^{\dagger}$ & 1.23 & 1.50 \\
\hline$d f$ & 7,181 & 8,180 & 7,181 & 8,180 & 7,181 & 8,180 \\
\hline Group Size & -.09 & -.09 & .01 & .01 & -.05 & -.06 \\
\hline Group Gender Diversity & $-.15^{\star}$ & -.15 & $-.16^{*}$ & $-.16^{*}$ & -.08 & -.07 \\
\hline Group Racial Diversity & -.09 & -.09 & -.04 & -.05 & -.08 & -.09 \\
\hline Group Tenure Diversity & .08 & .08 & .04 & .05 & .04 & .05 \\
\hline Manager Gender & .00 & .05 & -.07 & -.07 & -.04 & -.02 \\
\hline Manager Race & -.01 & -.01 & -.05 & -.05 & -.07 & -.07 \\
\hline Manager Tenure & .05 & .00 & .00 & .01 & .11 & .11 \\
\hline Extraversion & & -.01 & & -.03 & & -.11 \\
\hline$\Delta R^{2}$ & .06 & .00 & .04 & .00 & .05 & .01 \\
\hline$\Delta F$ & 1.63 & .02 & .95 & .16 & 1.23 & 2.35 \\
\hline$d f$ & 7,181 & 1,180 & 7,181 & 1,180 & 7,181 & 1,180 \\
\hline$R^{2}$ & .06 & .06 & .04 & .04 & .05 & .06 \\
\hline Adjusted $R^{2}$ & .02 & .02 & .00 & -.01 & .01 & .02 \\
\hline Overall $F$ & 1.63 & 1.42 & .95 & .85 & 1.23 & 1.38 \\
\hline$d f$ & 7,181 & 8,180 & 7,181 & 8,180 & 7,181 & 8,180 \\
\hline $\begin{array}{l}\text { Note. } \\
n=194 \text { groups. Standardize } \\
\text { size refers to number of emp } \\
\text { group tenure was calculated } \\
\text { male and } 0 \text { for female. Race } \\
{ }^{*} p<.05 .{ }^{\dagger} p<.10 .\end{array}$ & 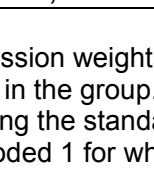 & 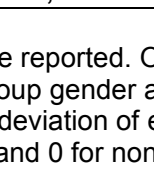 & oyee t & & 3. & $\begin{array}{l}\text { ses. Group } \\
\text { dex, and } \\
11 \text { for }\end{array}$ \\
\hline
\end{tabular}


favorable interpersonal, informational, and procedural justice climates. Thus, hypothesis 1 was supported.

Hypothesis 2 posited that leader conscientiousness would be positively related to procedural and informational justice climates. Results revealed that there was a significant positive relationship between conscientiousness and procedural justice climate $(\beta=.14, p<.05)$, but not informational justice climate $(\beta=.07, p>.05)$. As expected there were no significant results for interpersonal justice climate $(\beta=.12, p>.05)$. Conscientious leaders were more likely to lead groups in which subordinates perceived a more favorable procedural justice climate. Thus, hypothesis 2 was partially supported.

Hypothesis 3 posited that leader neuroticism would be negatively related to procedural, interpersonal, and informational justice climates. Results revealed significant negative relationships between neuroticism and procedural justice climate $(\beta=-.15, p<.05)$, interpersonal justice climate $(\beta=-.20, p<.01)$, and informational justice climate $(\beta=-.13, p<.05)$. Thus, hypothesis 3 was supported. A leader that lacked emotional stability tended to have subordinates that had less favorable perceptions of procedural, interpersonal, and informational justice climates.

Hypothesis 4 posited that leader extraversion would be positively related to a procedural justice climate. Results revealed that there was not a significant relationship for procedural justice climate $(\beta=-.01, p>.05)$. As expected, there were non-significant findings for interpersonal justice climate $(\beta=-.03, p>.05)$ and informational justice climate $(\beta=-.10, p>.05)$. Leader extraversion was not significantly related to any of the justice climates. Thus, hypothesis 4 was not supported. ${ }^{3}$

Hypotheses 1-4 were all tested with one personality dimension entered in each regression analysis. However, we deemed it important to also examine the multivariate effect of the leader personality dimensions on the justice climates (i.e., the unique effect of each personality dimension controlling for the other personality dimensions). We entered the control variables in Step 1 and the five personality dimensions in Step 2. For procedural justice climate, 
the only significant control variable was group gender diversity $(\beta=-.45, p=.05)$. In addition, none of the five personality dimensions reached statistical significance when all were entered at the same time. In terms of interpersonal justice climate, the only significant control variable was group gender diversity $(\beta=-.49, p<.05)$. In addition, neuroticism $(\beta=-.16, p<.05)$ remained a significant predictor of interpersonal justice climate. Finally, in terms of informational justice climate, none of the control variables were statistically significant. Agreeableness $(\beta=.22, p<.05)$ remained a significant predictor of informational justice climate, and extraversion $(\beta=-.17, p<.05)$ now demonstrated a significant relationship with informational justice climate. Thus, there were some consistencies in the bivariate and multivariate analyses, but the results were stronger when each personality dimension was entered in its own regression analysis. The primary conclusion from the multivariate analyses is that neuroticism is consistently related to the justice climates even after controlling for the other personality dimensions.

Hypothesis 5 posited that the relationships between individual justice perceptions and individual outcomes would be moderated by justice climate such that the relationship would be stronger when justice climate was high. The results of hypothesis 5 are presented in Table 3 . As predicted, the interactive effects of individual justice perceptions and justice climate on job satisfaction were significant for interpersonal justice $\left(b=.09, p<.01, R^{2}\right.$ between $\left.=.02\right)$ and informational justice $\left(b=.08, p<.05, R_{\text {between }}^{2} .02\right)$, but not for procedural justice $(b=.05, p>.05$, $R_{\text {between }}^{2}=.00$ ). See Figures 1 and 2 for plots of the significant interactions. Similarly, the interactive effects for individual justice perceptions and justice climate on commitment were significant for interpersonal justice $\left(b=.09, p<.05, R^{2}\right.$ between $\left.=.08\right)$ and informational justice $(b=.08$, $\left.p<.05, R_{\text {between }}^{2} .01\right)$, but not for procedural justice $\left(b=.02, p>.05, R^{2}\right.$ between $\left.=.00\right)$. See Figures 3 and 4 for plots of the significant interactions. In sum, the relationship between individual interpersonal and informational justice perceptions and individual outcomes depend on the justice climates such that the relationships increase in strength when justice climates are high. Thus, hypothesis 5 was largely supported. 
Table 3

HLM Results For the Interaction Between Justice Climates and Individual Justice Perceptions

(Hypothesis 5)

\begin{tabular}{|c|c|c|}
\hline & Job Satisfaction & Commitment \\
\hline \multicolumn{3}{|l|}{ Procedural Justice } \\
\hline Intercept & $2.63^{* *}$ & $2.96^{\star *}$ \\
\hline Group Size & $.01^{* *}$ & .00 \\
\hline Group Gender Diversity & $-.23^{*}$ & .00 \\
\hline Group Racial Diversity & .01 & .18 \\
\hline Group Tenure Diversity & -.05 & -.07 \\
\hline Individual Procedural Justice (1) & $.22^{\star *}$ & $.49^{* *}$ \\
\hline Procedural Justice Climate (2) & .04 & -.05 \\
\hline $1 \times 2$ & .05 & .02 \\
\hline \multicolumn{3}{|l|}{ Interpersonal Justice } \\
\hline Intercept & $2.41^{* *}$ & $2.87^{* *}$ \\
\hline Group Size & $.01^{*}$ & .00 \\
\hline Group Gender Diversity & -.30 & -.08 \\
\hline Group Racial Diversity & -.06 & .09 \\
\hline Group Tenure Diversity & -.07 & -.08 \\
\hline Individual Interpersonal Justice (1) & -.05 & -.03 \\
\hline Interpersonal Justice Climate (2) & -.00 & .00 \\
\hline $1 \times 2$ & $.09^{* *}$ & $.09^{* *}$ \\
\hline \multicolumn{3}{|l|}{ Informational Justice } \\
\hline Intercept & $2.51^{* *}$ & $2.81^{* *}$ \\
\hline Group Size & $.01^{*}$ & .00 \\
\hline Group Gender Diversity & $-.28 *$ & -.06 \\
\hline Group Racial Diversity & -.06 & .11 \\
\hline Group Tenure Diversity & -.07 & -.09 \\
\hline Individual Informational Justice (1) & -.01 & .10 \\
\hline Informational Justice Climate (2) & .02 & .02 \\
\hline $1 \times 2$ & $.08^{*}$ & $.08^{*}$ \\
\hline \multicolumn{3}{|c|}{$\begin{array}{l}\text { Note. } \quad n=3,371 \text { individuals in } 383 \text { groups, two-tailed tests of significance. All } \\
\text { values refer to estimations }(b) \text { of the fixed effects. ICC } 1 \text { value for job satisfaction }=.06, \\
\text { ICC1 value for commitment }=.05 \text {. Group size refers to number of employees in the } \\
\text { group. Group gender and racial diversity were calculated using Blau's index, and group } \\
\text { tenure was calculated by taking the standard deviation of employee tenure in the } \\
\text { group. } \\
{ }^{* \star} p<.01 .{ }^{*} p<.05 \text {. }\end{array}$} \\
\hline
\end{tabular}


Figure 1

Interaction between Individual Interpersonal Justice Perceptions and Interpersonal Justice Climate on Individual Job Satisfaction

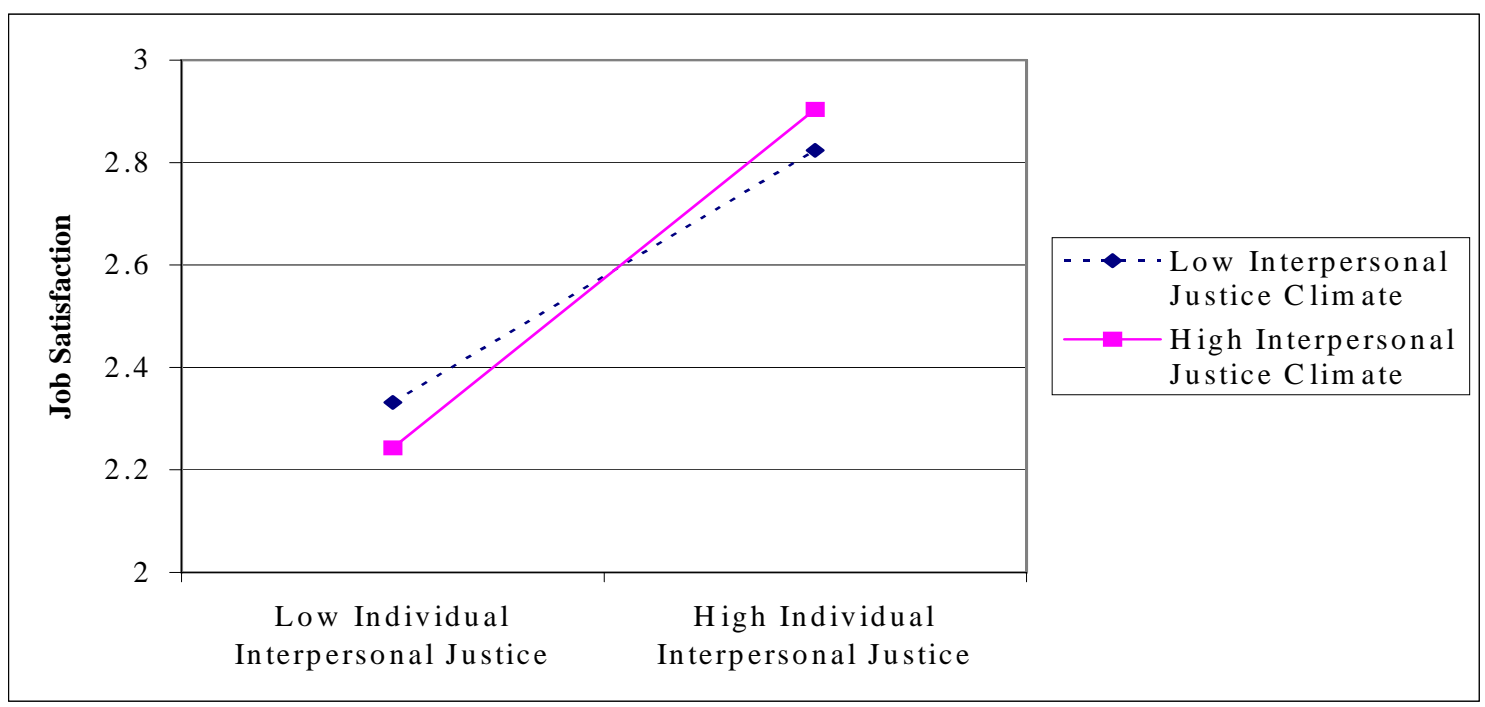

Figure 2

Interaction between Individual Interpersonal Justice Perceptions and Interpersonal Justice Climate on Individual Commitment

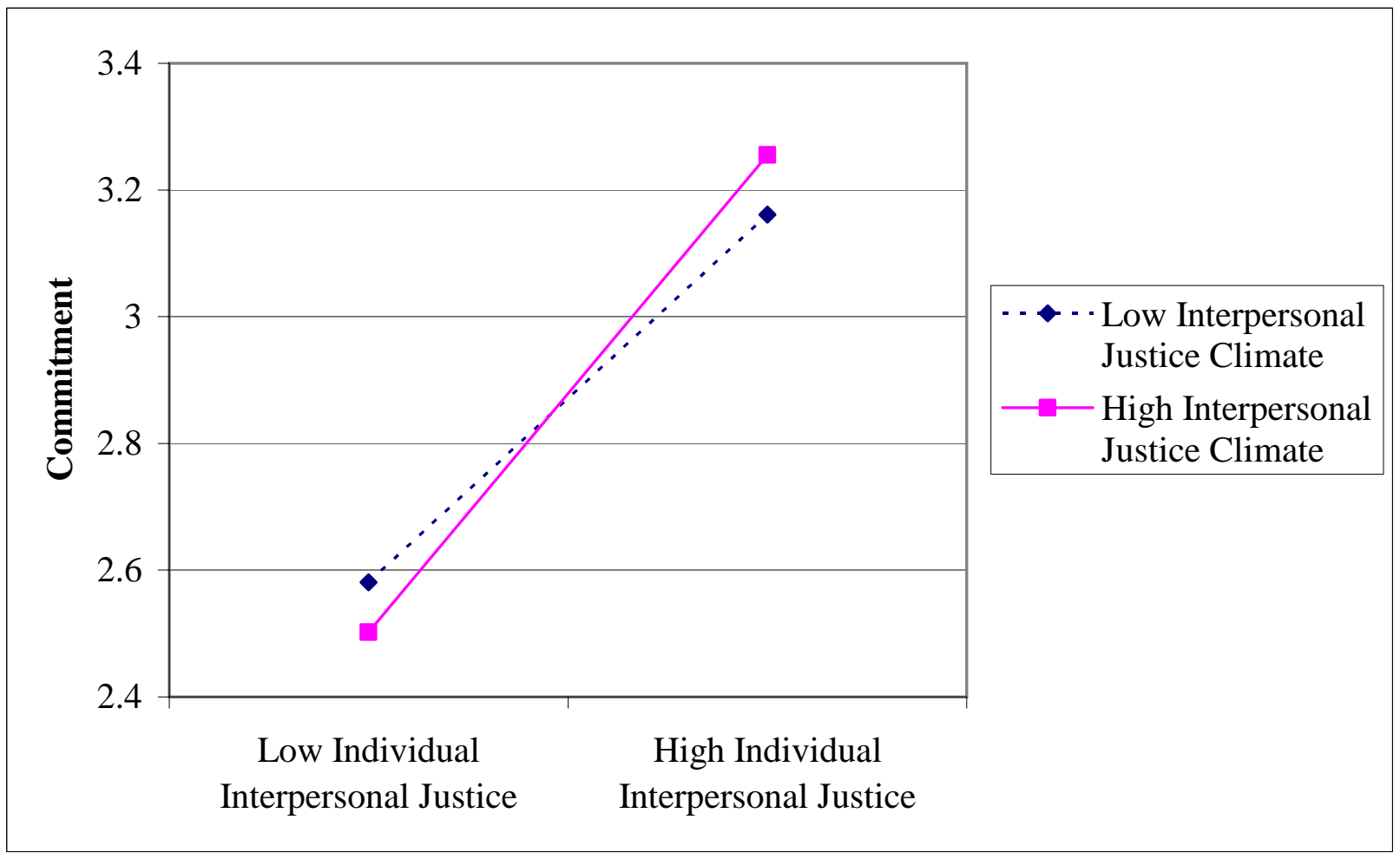


Figure 3

Interaction between Individual Informational Justice Perceptions and Informational Justice Climate on Individual Job Satisfaction

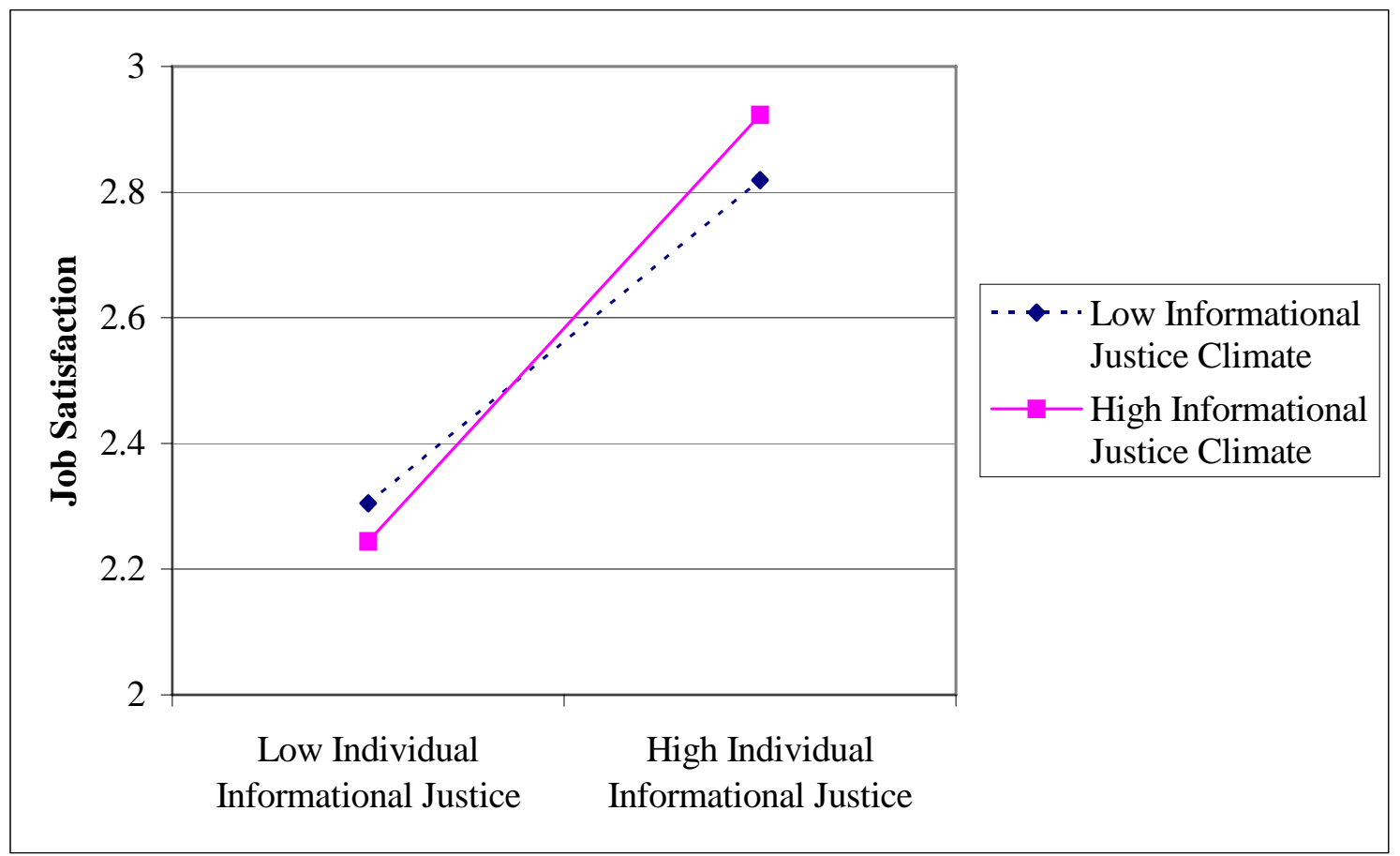

Figure 4

Interaction between Individual Informational Justice Perceptions and Informational Justice Climate on Individual Commitment

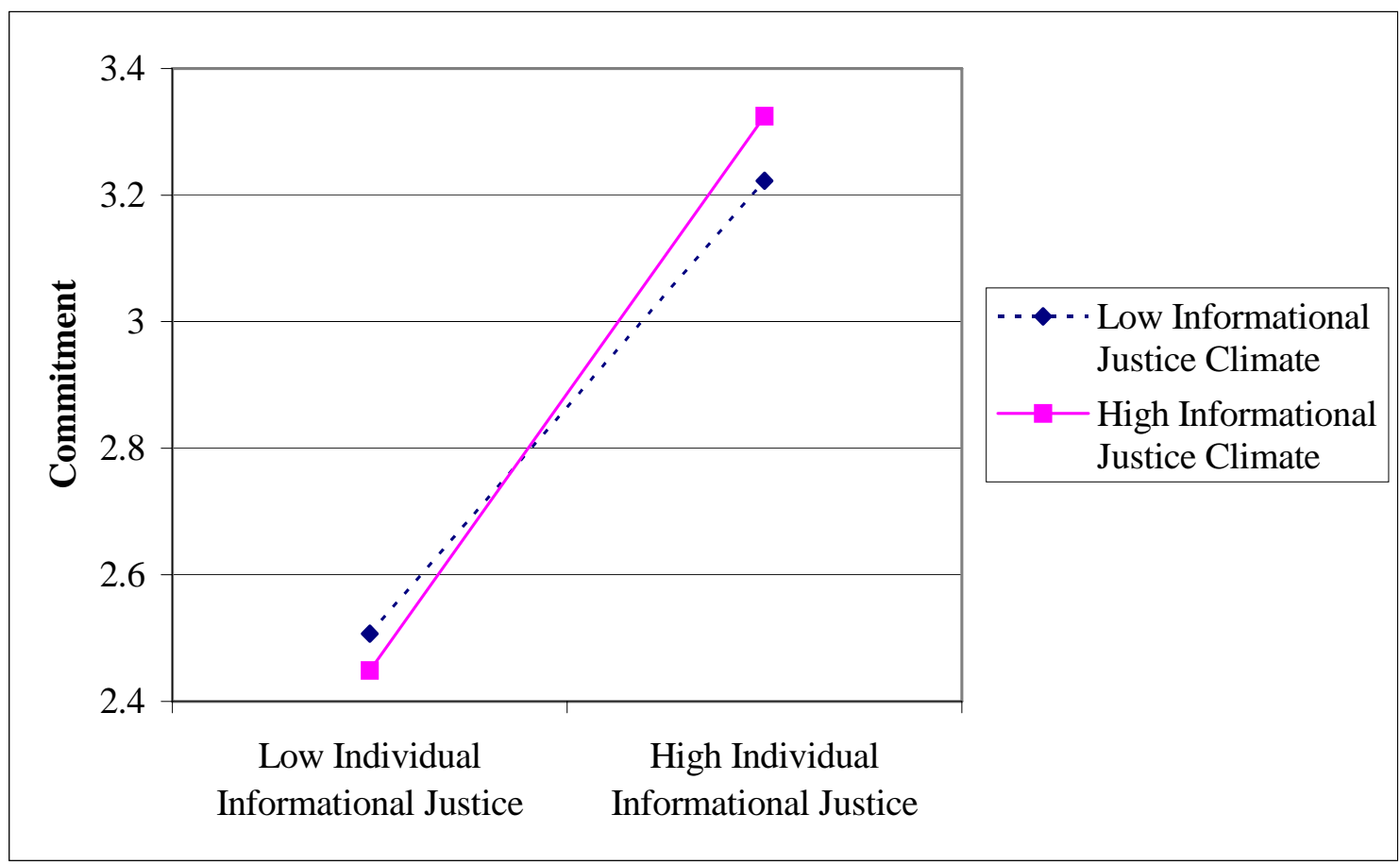




\section{Discussion}

The goals of this study were to examine the relationships between leader personality and employee perceptions of three justice climates, and also to explore the moderating role of justice climates on the effects of individual-level justice perceptions on other employee attitudes. Largely consistent with hypotheses derived from procedural (Leventhal, 1980; Thibaut \& Walker, 1975) and interactional justice (Bies \& Moag, 1996; Greenberg, 1993) theories, and research on leadership and personality, we found that leader agreeableness was positively related to procedural, interpersonal, and informational justice climates, leader conscientiousness was positively related to a procedural justice climate, and leader neuroticism was negatively related to all three justice climates. In addition, we found that justice climates moderated the relationship between individual level justice perceptions and job attitudes (e.g., job satisfaction, commitment), such that the relationships were stronger when justice climates were high.

\section{Theoretical Implications}

This research has implications for theory linking leadership to justice rules and ultimately justice climates, and the integration of organizational justice (e.g., group-value model, fairness theory) and social comparison theories. In terms of theory linking leadership to justice rules and ultimately justice climates, this research demonstrated a relationship between leader personality and the production of justice climates. To our knowledge, this is the first study to examine the effects of leader personality on subordinates' justice perceptions-which we think is an important area of research given all of the attention that has been paid to the effects of leadership on the development of climate-especially a climate regarding the treatment of followers (McGregor, 1960). Consistent with our theoretically-derived hypotheses based largely on procedural, interpersonal, and informational justice rules (Bies and Moag, 1986; Colquitt, 2001; Greenberg, 1993; Leventhal, 1980; Thibaut and Walker, 1975), the findings suggest that leaders do play an important role in the development of justice climates.

Specifically, agreeable leaders tended to lead departments that had employees who had a shared sense of interpersonal and informational justice. Due to their concern for others, 
agreeable leaders were likely more successful in communicating respect, avoiding impropriety, and providing candid justifications for decisions that were tailored to employees' needs. While we acknowledge that agreeable leaders are more trustworthy and thus may be viewed as more ethical, we did not make a hypothesis linking agreeableness and procedural justice because we felt that just because a leader is warm and easy to get along with does not mean they will provide consistent treatment, be more accurate, or satisfy other procedural justice rules. However, we did find that procedural justice was positively related to agreeableness. It appears that agreeable leaders excel in terms of interpersonal treatment and may also be more adept to behave in ways that satisfy procedural justice rules. Conscientious leaders, on the other hand, tended to lead departments that perceived procedural justice but not interpersonal or informational justice. A potential explanation for this finding is that while agreeable leaders tend to focus more on interpersonal sensitivity, conscientious leaders' dutiful nature helps them behave in ways that satisfy the more task-oriented, procedural justice rules such as accuracy, consistency, ethicality, and voice, as opposed to the rules that require interpersonal sensitivity. The non-significant relationship with informational justice climates was surprising. It is perhaps the case that their preoccupation with order, exacting nature, strict adherence to a schedule, and focus on ensuring their tasks and duties get accomplished, does not allow time to communicate valuable information to subordinates. Alternatively, given that conscientiousness involves achievement-striving, perhaps conscientious leaders are concerned about their own well-being, but less so about making sure all group members receive adequate justifications. Future research that replicates and further explains the nature of this relationship would be useful.

Consistent with our hypothesis, neurotic leaders led departments that had less favorable justice climates across all three of the assessed dimensions. Neurotic leaders were probably less able to be consistent to all employees because of their emotional instability, less likely to be accurate because they are easily disturbed and distracted by their own anxiety, and less likely to provide voice for fear that the feedback will increase their anxiety. Thus, due to the anxiety and moodiness that tends to characterize neurotic individuals, their self-focused nature may 
have made it difficult for them to ensure that respect is expressed, impropriety avoided, and truthful justifications provided. Accordingly, neurotic leaders in our sample were less likely to satisfy procedural, interpersonal, and informational justice rules. Finally, contrary to our predictions, extraversion was not related to any of the three justice climates. We reasoned that the value extraverts place on voice would lead them to behave in ways that promote procedural justice, however, it is possible that just because extraverted leaders like to have voice themselves, they may not necessarily be motivated to ensure that they provide subordinates with the opportunity to express their concerns. In addition, because one aspect of extraversion is assertiveness (or dominance), such qualities may prevent them from actually listening to subordinates' opinions. Future research using a measure of extraversion that taps the dominance sub-facet of extraversion would be useful for exploring this explanation.

In addition to the bivariate relationships between the personality dimensions and the justice climates, we also provided a multivariate test of the personality dimensions. The primary conclusion from this additional analysis is that neuroticism may be the most important personality dimension when considering a leader's tendency to treat employees fairly. Given the demands of being a manager, being able to remain stable under times of stress may be the most important personality characteristic in understanding whether leaders treat their employees fairly. Given the multicollinearity between the various personality dimensions, it is not surprising that the results for the multivariate analysis yielded less significant effects than the bivariate relationships.

In terms of the integration of organizational justice (e.g., group-value model, fairness theory) and social comparison theories, the present research has some noteworthy implications. Consistent with social comparison theory, our data revealed that the relationship between individual justice perceptions and individual attitudinal outcomes (e.g., satisfaction, commitment), were moderated by justice climates such that the relationships were stronger when justice climates were high. While the effect size of these findings is small, they do lend support for both a content model of justice (e.g., group-value model) that examines why people care about justice, and a process model of justice (e.g., fairness theory) that attempts to explain 
how justice judgments are formed. In support of the group-value or relational model (Lind \& Tyler, 1998; Tyler \& Lind, 1992), when individual justice was high and justice climate was high, outcomes were most favorable. In this situation, the subordinate likely believed that all employees are important and valued to the organization and thus their attitudes were even more favorable. In contrast, when individual justice was high but justice climate was low, it perhaps suggests to the subordinate that there is not an inclusive environment where all employees are valued-and thus the possibility that this individual could be less valued in the future seems like a more realistic prospect. In support of fairness theory (Folger \& Cropanzano, 1998; 2001), when the group is treated well but an individual perceives that s/he is treated unfairly, that individual is more likely to believe that something could have been done about it and subsequently satisfaction and commitment are less favorable. Interestingly, when both the individual and group are low on justice, it is less clear whether anything "could" have been done. Perhaps the leader is overwhelmed with a busy workload and does not have enough time for interpersonal interactions, or does not have the autonomy to implement procedures. While justice perceptions will be less favorable, it isn't clear whether employees will attribute blame to the leader.

\section{Practical Implications}

One important practical implication of this research is that it may behoove organizations to select and/or promote the kinds of leaders who are capable of creating fair climates where most, if not all, members perceive fair treatment, for such climates may be associated with a number of types of performance outcomes through the mediating mechanisms of job satisfaction, commitment and other job-related attitudes. One advantage of examining leader personality as opposed to leader behaviors is that it is possible to assess the personality of potential managers but not possible to assess actual behaviors on the job prior to employment. The findings regarding neuroticism, coupled with the results for agreeableness and conscientiousness, suggest that it is important for organizations to select managers who can handle the many stresses of the job, are interpersonally sensitive, and are organized and dutiful. 
While we did not measure mediating variables in the relationship between leader personality and justice climate, a premise of this research, as discussed above, is that leader personality impacts justice climates through the behaviors of leaders. Thus, in addition to selection, training could be provided to managers to make them aware of the various procedural, interpersonal, and informational justice rules, as well as the associated behaviors in which they can engage to help ensure that all of their employees perceive fair treatment. Indeed, some research has already demonstrated that justice training can improve manager's ability to adhere to justice rules (Greenberg, 2006; Skarlicki \& Latham, 1997). Such training could suggest interventions such as facilitating meetings in which subordinates are able to express their opinions and information is well-communicated, role-playing interpersonal sensitivity when providing performance appraisal feedback to subordinates, and establishing policies that increase the likelihood of procedural and informational justice rule satisfaction. Given the many detrimental effects of abusive supervision, perhaps justice training could help provide abusive leaders with more effective strategies for interacting with subordinates-and at the very least elucidates the notion that the organization cares about how employees are treated and that belittling, ridiculing, and putting down subordinates will not be tolerated. Essentially, if leaders with the "right" personality are not selected then at least an attempt can be made to train the behaviors that effective leaders intuitively exhibit.

A third practical implication of this research is that it is important for organizations to ensure they communicate relevant information to employees. If organizations assume some responsibility for explaining changes in practices and policies, and design "strong" human resource management systems that are high in distinctiveness, consistency, and consensus (Bowen \& Ostroff, 2004), some of the burden is relieved from each manager. While interpersonal justice will likely result from the interpersonal treatment of one's manager, perceptions of informational justice as well as procedural justice can be improved from information communicated by higher levels of management, and by organizational policies and practices, more generally. 


\section{Future Research Directions}

We believe the findings of this research have implications for future research. For example, despite all that has been written about the importance of leadership on justice perceptions, researchers have yet to understand what it is about certain leaders that result in behaviors that make their followers perceive they have been fairly treated. While we provide an initial examination of this notion by looking at the relationship between leader personality and justice climates, and in developing our hypotheses highlight leadership behaviors or tendencies that might explain these relationships, we do not know the actual behaviors by which leaders with these characteristics create perceptions of a fair environment (see Ehrhart, 2004 for an exception). We allude to a number of possible mechanisms (e.g., satisfying various procedural, interpersonal, and informational justice rules); however, future research should examine the behavioral mediators between leader attributes and justice perceptions to better understand how to create perceptions of fair leadership. For example, fair leaders may hold meetings with their department members to specifically address their problems and solicit their opinions. Or perhaps leaders who are perceived as fair spend more one-on-one time with subordinates, thereby building rapport in ways that facilitate justice perceptions. While this study was concerned with the "who" question of fair leadership, future research should examine the "how" question to better understand what leaders actually do to be perceived as more fair. Thus, an examination of mediators of the relationship between leader personality and justice climates appears to be an obvious and fruitful next step.

A second important area for future research involves how justice operates within a group context. For example, what are the processes by which groups collectively determine how fairly they are treated? Does having dispersion in justice perceptions negatively impact individual and group outcomes? When do team members pay most attention to the treatment of others in the group? In the present study, individuals with high justice perceptions had the most favorable outcomes when other group members also had high justice perceptions. Consistent with social comparison theory, are there contexts when individuals would prefer to be treated more favorably than other group members? It might be, for example, that individuals who have 
historically suffered injustices_either in a general sense as a member of a historically disadvantaged group, or as an individual in past experiences with the particular leader-feel entitled to receive better treatment than others. Such a supposition would require longitudinal examinations of justice perceptions to see how prior experiences influence reactions to future justice experiences, and/or in-depth examinations of the relationship between individual and group demographics and justice experiences. Each of these questions is important to address in future research.

A third avenue for future research is to use a more fine-grained measure of personality and to link such measures to both mean levels of justice climate as well as to variance in justice climates (referred to as justice climate strength). As alluded to previously, perhaps some of the non-significant findings in this research were a result of using broad dimensions of personality as opposed to facet-level measures that more directly map on to specific justice rules. Future research should address this limitation by examining theoretically-driven facet-level measures of personality to justice climates. In addition, given the important role of leadership in the literature on climate emergence, it makes sense that certain types of leaders are better able to create a shared reality among their followers. While we did not find any direct effects between the FFM and justice climate strength, perhaps examining the effects of facets of the FFM could be useful for linking leader personality to justice climate strength.

Finally, consistent with long-standing recognition that behavioral phenomena are a function of both personality and situations (Mischel, 1977), we believe that it is important to give situational factors greater attention in future research. Although in our current research we focus only on the internal properties of leaders, our intention is not to discount the potential importance of external conditions that constrain the behavior of leaders (and the influence of their personality in determining the creation of justice climates) and also directly influence the justice perceptions of employees. Consistent with research on situational strength, for example, we might expect that leader personality exerts a weaker effect on justice climates in strong organizational cultures than in weak ones. If supported, such a hypothesis has important practical implications because it would suggest that even though we have found significant 
effects of leader personality on justice climates, there may be ways to "over-ride" such effects, at least partially, by holding employees accountable to strong organizational norms of the type that are relevant for justice perceptions.

\section{Limitations}

Like all research, the present study has limitations. One limitation was the fact that the data were cross-sectional, so it is difficult to draw causal conclusions about the relationships described in the paper. However, it is unlikely that leader personality was caused by employee perceptions of the justice climates and longitudinal research supports the causal chain of justice perceptions leading to attitudinal outcomes rather than vice versa (see Ambrose \& Cropanzano, 2003 for an example). A second limitation is that our outcomes were attitudinal in nature and were collected from the same employees who provided justice data. In the future, more objective data that are focused on behavioral (e.g., OCB) and/or other outcomes (e.g., customer satisfaction) should also be examined. A third limitation is the response rate which is slightly lower than desired, but similar to other large-scale survey projects (Roth \& BeVier, 1998). A fourth limitation is the fact that shortened justice scales were used in the present research. For example, only four procedural justice items were assessed and thus only four procedural justice rules were tapped (e.g., consistency, accuracy, ethicality, and voice). We selected these items based on the factor loadings presented in Colquitt's (2001) scale development paper and the extent to which the rules were well represented in the procedural justice literature. Because each item in the justice scales represents a specific justice rule, we only discussed justice rules for items that were assessed. In addition, consistent with recent work on interpersonal and informational justice climate (Liao \& Rupp, 2005; Simons \& Roberson, 2003), we assessed interpersonal and informational justice climate using the department leader as the referent as opposed to assessing the justice dimensions using both individual- and group-level referents. Future research should also examine the effects of interpersonal and informational justice climates using the group, team, unit, department, store, or organization as the referent like the work on procedural justice climate has done. 
A final limitation of the present study is the interpretive complexity introduced by the strong relationships among the three forms of justice climates. This can be a problem because it calls into question the distinctiveness of each justice dimension. However, these results are not inconsistent with research at the individual level that has found a corrected correlation of .66 between interpersonal and informational justice, .63 between interpersonal and procedural justice, and .58 between procedural justice and informational justice (Colquitt et al., 2001). Similarly, Simons and Roberson (2003) found a correlation between procedural justice and interpersonal justice of .87 once it had been aggregated to the business-unit level. In support of the distinctiveness of the dimensions, however, we do find that the different dimensions do have different personality determinants and demonstrate different interaction effects, and a confirmatory factor analysis did support the three-factor solution. In a related point, we did not assess distributive justice in this study so future research that examines antecedents and consequences of distributive justice climate could help expand our understanding of justice at an aggregate level.

\section{Conclusions}

While McGregor (1960) long ago proposed fairness and trust as keys to managerial effectiveness, his notions have not since received the attention they perhaps deserve. McGregor in fact saw the creation of a "managerial climate" as one based on fairness and trust and that it was fairness and trust that in turn produced more effective group outcomessuggesting that justice climates should potentially be viewed as a domain of leader effectiveness. The present research sought to build on McGregor's work by exploring who is able to create such a climate. 


\section{Footnotes}

${ }^{1}$ When making hypotheses regarding justice climate we are referring to mean levels of justice perceptions within a group. While considerable research has emerged examining justice climate strength (i.e., the variance in group members' justice perceptions; see Colquitt et al., 2002), we did not think there was sufficient theoretical justification for examining the relationship between leader personality and justice climate strength. Consistent with our rationale, we created justice climate strength variables by taking the standard deviation of individual justice perceptions within each group (Harrison and Klein, in press). Results of these exploratory analyses demonstrated non-significant effects for all of the personality dimensions on procedural, interpersonal, and informational justice climate strength.

${ }^{2}$ Hypothesis 5 does not include differential predictions for the three dimensions of justice for a number of reasons. First, there is not a compelling theoretical rationale for making different predictions for the three justice dimensions. While prominent justice theories acknowledge distinctions among the dimensions, they generally support the notion that the various dimensions are functionally similar in many contexts (Cropanzano, Byrne, Bobocel, \& Rupp, 2001; Cropanzano, Rupp, Mohler, \& Schminke, 2001). Second, there is theoretical and empirical support that social comparisons take place with regard to both procedural justice (Brockner, Konovsky, Cooper-Schneider, Folger, Martin, \& Bies, 1994) and interactional justice (Lamertz, 2002), and that the nature of that social comparison process is similar regardless of the dimension of justice being considered.

${ }^{3}$ While we did not find sufficient theoretical support to forward hypotheses about openness to experience and the justice climates, we still assessed openness to experience and conducted exploratory analyses. Consistent with our rationale, results of regression analyses revealed non-significant effects for openness to experience on procedural $(\beta=.07, p>.05)$, interpersonal $(\beta=.04, p>.05)$, and informational $(\beta=.00, p>.05)$ justice climates. 


\section{References}

Adams, J. S. (1965). Inequity in social exchange. In L. Berkowitz (Ed.), Advances in experimental social psychology (Vol. 2, pp. 267-299). New York: Academic Press.

Ambrose, M. L., \& Cropanzano, R. (2003). A longitudinal analysis of organizational fairness: An examination of reactions to tenure and promotion decisions. Journal of Applied Psychology, 88, 266-275.

Aquino, K., \& Bradfield, M. (2000). Perceived victimization in the workplace: The role of situational factors and victim characteristics. Organizational Science, 11, 525-537.

Avery, D. R. (2003). Personality as a predictor of the value of voice. The Journal of Psychology, 137, 435-446.

Bass, B. M. (1990). Bass and Stogdill's handbook of leadership. New York: Free Press.

Bies, R. J. (2001). Interactional (in)justice: The sacred and the profane. In J. Greenberg \& R. Cropanzano (Eds.), Advances in organizational justice (pp. 89-118). San Francisco: Stanford University Press.

Bies, R .J., \& Moag, J. F. (1986). Interactional justice: Communication criteria of fairness. In R. J. Lewicki, B. H. Sheppard, \& M. H. Bazerman (Eds.), Research on negotiations in organizations (Vol.1, pp. 43-55). Greenwich, CT: JAI Press.

Bies, R. J., \& Tripp, T. M. (1998). Two faces of the powerless: Coping with tyranny. In R. M. Kramer \& M. A. Neale (Eds.), Power and influence in organizations (pp. 203-219). Thousand Oaks, CA: Sage.

Bliese, P. D. (2000). Within group agreement, non-independence, and reliability: Implications for data aggregation. In K. J. Klein \& S. W. J. Kozlowski (Eds.), Multilevel theory, research, and methods in organizations: Foundations, extensions, and new directions (pp. 349-381). San Francisco: Jossey-Bass.

Bowen, D. E., \& Ostroff, C. (2004). Understanding HRM-firm performance linkages: The role of the "strength" of the HRM system. Academy of Management Review, 29, 203-221.

Brockner, J., Konovsky, M., Cooper-Schneider, R., Folger, R., Martin, C., \& Bies, R. (1994). Interactive effects of procedural justice and outcome negativity on victims and survivors of job loss. Academy of Management Journal, 37, 397-409.

Buckingham, J. T., \& Alicke, M. D. (2002). The influence of individual versus aggregate social comparison and the presence of others on self-evaluations. Journal of Personality and Social Psychology, 83, 1117-1130.

Cohen-Charash, Y., \& Spector, P. E. (2001). The role of justice in organizations: A metaanalysis. Organizational Behavior and Human Decision Processes, 89, 278-321.

Colquitt, J. C. (2001). On the dimensionality of organizational justice: A construct validation of a measure. Journal of Applied Psychology, 86, 386-400.

Colquitt, J. C. (2004). Does the justice of the one interact with the justice of the many? eactions to procedural justice in teams. Journal of Applied Psychology, 89, 633-646.

Colquitt, J. A., Conlon, D. E., Wesson, M. J., Porter, C. O. L. H., \& Ng, K. Y. (2001). Justice at the millennium: A meta-analytic review of 25 years of organizational justice research. Journal of Applied Psychology, 86, 425-445.

Colquitt, J. A., Noe, R. A., \& Jackson, C. L. (2002). Justice in teams: Antecedents and consequences of procedural justice climate. Personnel Psychology, 55, 83-109.

Colquitt, J. A., Zapata-Phelan, C. P., \& Roberson, Q. M. (2005). Justice in teams: A review of fairness effects in collective contexts. In J. J. Martocchio (Ed.), Research in personnel and human resource management (Vol. 24, pp. 53-94). Oxford, UK: Elsevier.

Costa, P. T. \& McCrae, R. R. (1992). Revised NEO Personality Inventory (NEO-PIR): Professional Manual, Psychological Assessment Resources, Inc.

Costa, P. T. \& McCrae, R. R., \& Dembrowski, T. M. (1989). Agreeableness vs. antagonism: Explication of a potential risk factor for CHD. In A. Siegman \& T. M. Dembrowski (Eds.), In search of coronary-prone behavior (pp. 41-63). Hillsdale, NJ: Erlbaum. 
Cropanzano, R., Byrne, Z. S., Bobocel, D. R., \& Rupp, D. E. (2001). Moral virtues, fairness heuristics, social entities, and other denizens of organizational justice. Journal of Vocational Behavior, 58, 164-209.

Cropanzano, R., Rupp, D. E., Mohler, C. J., \& Schminke, M. (2001). Three roads to organizational justice. In J. Ferris (Ed.), Research in personnel and human resources management (Vol. 20, pp. 1-113). Greenwich, CT: JAI Press.

Crosby, F. (1976). A model of egoistic relative deprivation. Psychological Review, 83, 85-113.

Dietz, J., Robinson, S. L., Folger, R., Baron, R. A., \& Schulz, M. (2003). The impact of community violence and an organization's procedural justice climate on workplace aggression. Academy of Management Journal, 46, 317-326.

Ehrhart, M. G. (2004). Leadership and procedural justice climate as antecedents of unit-level organizational citizenship behavior. Personnel Psychology, 57, 61-94.

Festinger, L. (1954). A theory of social comparison processes. Human Relations, 7, 117-140.

Folger, R. (1986). A referent cognitions theory of relative deprivation. In J. M. Olson, C. P. Herman, \& M. P. Zanna (Eds.), Relative deprivation and social comparison: The Ontario symposium (Vol. 4, pp. 33-55). Hillsdale, NJ: Erlbaum.

Folger, R., \& Cropanzano, R. (1998). Organizational justice and human resource management. Thousand Oaks, CA: Sage.

Folger, R., \& Cropanzano, R. (2001). Fairness theory: Justice as accountability. In J. Greenberg \& R. Cropanzano (Eds.), Advances in organizational justice (pp. 1-55). Palo Alto, CA: Stanford Press.

George, J. M. (1990). Personality, affect, and behavior in groups. Journal of Applied Psychology, 75, 107-116.

Goldberg, L. R. (1999). A broad-bandwith, public domain, personality inventory measuring the lower-level facets of several five-factor models. In I. Mervielde, I. Deary, F. De Fruyt, \& F. Ostendorf (Eds.), Personality psychology in Europe (Vol. 7, pp. 7-28). Tilburg, The Netherlands: Tilburg University Press.

Goodstein, L. D., \& Lanyon, L. D. (1999). Applications of personality assessment to the workplace: A review. Journal of Business and Psychology, 18, 533-553.

Greenberg, J. (1993). The social side of fairness: Interpersonal and informational classes of organizational justice. In R. Cropanzano (Ed.), Justice in the workplace: Approaching fairness in human resource management (pp. 79-103). Hillsdale, NJ: Erlbaum.

Greenberg, J. (2006). Losing sleep over injustice: Attenuating insomniac reactions to underpayment inequity with supervisory training in interactional justice. Journal of Applied Psychology, 91, 58-69.

Grienberger, I. V., Rutte, C., G., \& van Knippenberg, A. F. M. (1997). Influence of social comparisons of outcomes and procedures on fairness judgments. Journal of Applied Psychology, 82, 913-919.

Harrison, D. A., \& Klein, K. J. (in press). What's the difference? Dispersion constructs as separation, variety, or disparity in organizations. Academy of Management Review.

Ilgen, D. R., Hollenbeck, J. R., Johnson, M., \& Jundt, D. (2005). Teams in organizations: From I-P-O models to IMOI models. Annual Review of Psychology, 56, 517-543.

Judge, T. A., \& Bono, J. E. (2000). Five-factor model of personality and transformational leadership. Journal of Applied Psychology, 85, 751-765.

Keller, T. (1999). Images of the familiar: Individual differences and implicit leadership theories. Leadership Quarterly, 10, 589-608.

Kirkpatrick, S. A., \& Locke, E. A. (1991). Leadership: Do traits matter? Academy of Management Executive, 5, 48-60.

Klein, K. J., Dansereau, F., \& Hall, R. J. (1994). Levels issues in theory development, data collection, and analysis. Academy of Management Review, 19, 195-229.

Klein, K. J., \& Kozlowski, S. W. (2000). Multilevel theory, research, and methods in organizations. San Francisco, CA: Jossey-Bass, Inc. 
Kozlowski, S. W. J., \& Bell, B. S. (2003). Work groups and teams in organizations. In W. C. Borman, D. R. Ilgen, \& R. J. Klimoski (Eds.), Comprehensive handbook of psychology: Industrial and organizational psychology (Vol. 12, pp. 333-375). New York: Wiley.

Kunin, T. (1955). The construction of a new type of attitude measure. Personnel Psychology, 8, 65-78.

Lamertz, K. (2002). The social construction of fairness: Social influence and sense making in organizations. Journal of Organizational Behavior, 23, 19-37.

Leventhal, G. S. (1980). What should be done with equity theory? In K. J. Gergen, M. S. Greenberg, \& R. H. Willis (Eds.), Social exchange: Advances in theory and research (pp. 27-55). New York: Plenum Press.

Lewin, K., Lippitt, R., \& White, R. K. (1939). Patterns of aggressive behavior in experimentally created "social climates." Journal of Social Psychology, 22, 272-280.

Liao, H., \& Rupp, D. E. (2005). The impact of justice climate and justice orientation on work outcomes: A cross-level multifoci framework. Journal of Applied Psychology, 90, 242256.

Lind, E. A. (2001). Fairness heuristic theory: Justice judgments as pivotal cognitions in organizational relations. In J. Greenberg \& R. Cropanzano (Eds.), Advances in organizational justice (pp. 56-88). Stanford, CA: Stanford University Press.

Lind, E. A., \& Tyler, T. R. (1988). The social psychology of procedural justice. New York: Plenum.

Lindell, M. K., \& Brandt, C. J. (2000). Climate quality and climate consensus as mediators of the relationship between organizational antecedents and outcomes. Journal of Applied Psychology, 85, 331-348.

McGregor, D. (1960). The human side of enterprise. McGraw-Hill.

Meyer, J., \& Allen, N. (1991). A three-component conceptualization of organizational commitment. Human Resource Management Review, 1, 61-98.

Mischel, W. 1977. The interaction of person and situation. In D. Magnusson, \& N. S. Endler (Eds.), Personality at the crossroads: Current issues in interactional psychology. Hillsdale, NJ: Erlbaum.

Mossholder, K. W., Bennett, N., \& Martin, C. L. (1998). A multilevel analysis of procedural justice context. Journal of Organizational Behavior, 19, 131-141.

Naumann, S. E., \& Bennett, N. (2000). A case for procedural justice climate: Development and test of a multilevel model. Academy of Management Journal, 43, 881-889.

Offerman, L. R., \& Malamut, A. B. (2002). When leaders harass: The impact of target perceptions of organizational leadership and climate on harassment reporting and outcomes. Journal of Applied Psychology, 87, 885-893.

Roberson, Q. M., \& Colquitt, J. A. (2005). Shared and configural justice: A social network model of justice in teams. Academy of Management Review, 30, 595-607.

Roth, P. L., \& BeVier, C. A. (1998). Response rates in HRM/OB survey research: Norms and correlates, 1990-1994. Journal of Management, 24, 97-117.

Scandura, T. A. (1999). Rethinking leader-member exchange: An organizational justice perspective. Leadership Quarterly, 10, 25-40.

Schneider, B., \& Bowen, D. E. (1985). Employee and customer perceptions of service in banks: Replication and extension. Journal of Applied Psychology, 60, 318-328.

Schneider, B., Salvaggio, A. N., \& Subirats, M. (2002). Climate strength: A new direction for climate research. Journal of Applied Psychology, 87, 220-229.

Shah, P. S. (1998). Who are employees' referents? Using a network perspective to determine referent others. Academy of Management Journal, 41, 249-268.

Sheppard, B. H., \& Lewicki, R. J. (1987). Toward general principles of managerial fairness. Social Justice Research, 1, 161-176. 
Simons, T., \& Roberson, Q. (2003). Why managers should care about fairness: The effects of aggregate justice perceptions on organizational outcomes. Journal of Applied Psychology, 88, 432-443.

Singer, J. D. (1998). Using SAS PROC MIXED to fit multilevel models, hierarchical models, and individual growth models. Journal of Educational and Behavioral Statistics, 4, 323355.

Skarlicki, D. P., \& Latham, G.P. (1997). Leadership training in organizational justice to increase citizenship behavior within a labor union: A replication. Personnel Psychology, 50, 617634.

Spangler, W. D., House, R. J., \& Palrecha, R. (2004). Personality and leadership. In B. Schneider and D. B. Smith (Eds.), Personality and organizations (pp. 251-290). Hillsdale, NJ: Erlbaum.

Tepper, B. J. (2000). Consequences of abusive supervision. Academy of Management Journal, 43, 178-190.

Tepper, B. J., Duffy, M. K., \& Shaw, J. D. (2001). Personality moderators of the relationship between abusive supervision and subordinates' resistance. Journal of Applied Psychology, 86, 974-983.

Thibaut, J. W., \& Walker, L. (1975). Procedural justice: A psychological perspective. Hillsdale, NJ: Erlbaum.

Tyler, T. R., \& Lind, E. A. (1992). A relational model of authority in groups. In M. P. Zanna (Ed.), Advances in experimental social psychology (Vol. 25, pp. 115-191). San Diego, CA: Academic Press.

van den Bos, K., \& Lind, E. A. (2001). The psychology of own versus others' treatment: Selforiented and other-oriented effects on perceptions of procedural justice. Personality and Social Psychology Bulletin, 27, 1324-1333.

Wanous, J. P., Reichers, A. E., \& Hudy, M. J. (1997). Overall job satisfaction: How good are single-item measures? Journal of Applied Psychology, 82, 247-252.

Zohar, D. (2000). A group-level model of safety climate: Testing the effect of group climate on microaccidents in manufacturing jobs. Journal of Applied Psychology, 85, 587-596.

Zohar, D. (2002). Modifying supervisory practices to improve subunit safety: A leadership-based intervention. Journal of Applied Psychology, 87, 156-163.

Zohar, D., \& Luria, G. (2004). Climate as a social-cognitive construction of supervisory safety practices: Scripts as proxy for behavioral patterns. Journal of Applied Psychology, 89, 322-333. 